\title{
Behavior Mechanism of Internet Product Consumers Transferring from Personal Computer Terminal to Mobile Terminal
}

\author{
Wenjun Liu ${ }^{1}$, Lin Ding ${ }^{2 *}$, Cuibo Wang ${ }^{1}$, Baochun Zhao ${ }^{1}$ \\ ${ }^{1}$ School of Management, South-central University for Nationalities, Wuhan 430074, China \\ ${ }^{2}$ School of Accounting, Zhongnan University of Economics and Law, Wuhan 430073, China
}

Corresponding Author Email: linding@zuel.edu.cn

https://doi.org/10.18280/i2m.180206

Received: 11 January 2019

Accepted: 23 March 2019

Keywords:
behavioral transfer, brand extension,
continuance intention, perceived
integrity

\begin{abstract}
This paper attempts to disclose the reasons for consumers of the parent product at PC terminal to the extended product at the mobile terminal. Based on the classical theories of brand extension, technology acceptance and continuance intention, three new factors, namely, perceived integrity, irreplaceability and new value recognition, were introduced and a hypothetical model was put forward and tested through empirical analysis. The empirical results show that the satisfaction of the parent product does not affect the continuance intention of the extended product. Specifically, the perceived ease-of-use of the extended product mediates the relationship between the satisfaction of the parent product and the continuance intention of the extended product. The perceived irreplaceability of the extended product has a positive impact on the continuance intention, so do the new perceived value and perceived integrity.
\end{abstract}

\section{INTRODUCTION}

With the rapid proliferation of the mobile Internet, most Chinese consumers now access the Internet via both personal computers (PCs) and mobile devices. As a result, Internet service providers are competing to provide products for both $\mathrm{PC}$ and mobile terminals. However, some Internet services, once popular on the PC terminal, are no longer attractive to consumers on the mobile terminal. Thus, it is highly necessary to identify the reasons that affect the transferring of product consumers from the PC terminal to the mobile terminal.

The consumer behavior in the transfer from PC terminal to mobile terminal is a part of the brand extension research. The existing studies on brand extension of Internet products mainly tackle the extension of the Internet brand, including the effects of offline brand extension factors (e.g. perceived quality, extended product and correlation degree to the parent product) on consumer evaluation of Internet brand franchise extension. In 2010, Song et al. put forward a new concept called the perceived tie, i.e. the links on the main Internet product leading to the extended product. For example, the Baidu app provides links to its extended products like Baidu Tieba and Baidu Map on its main interface, so does Tencent to franchise extension products like QQ Games and QQ Mail on the main interface of QQ. Despite some subsequent discussions over this concept, there is no report on the behavioral mechanism of Internet product consumers transferring from the $\mathrm{PC}$ terminal to the mobile terminal.

Based on the classical theories of brand extension, technology acceptance and continuance intention, this paper introduces three new factors, namely, perceived integrity, irreplaceability and new value recognition, and then explores the reasons for online consumers to transfer from the PC terminal to the mobile terminal. In addition, a hypothetical model was put forward and tested through empirical analysis.

\section{THEORETICAL BASES AND RESEARCH MODEL}

\subsection{Brand extension theory}

In 1981, Tauber proposed the company growth matrix model for the market entry of new companies, giving birth to the brand extension theory. Starting with product category and brand name, Tauber's model calls the brand for extension as the parent product and the resulting product as the extended product. Between 1990 and 1992, Aaker and Keller successively conducted empirical studies on how to implement brand extension strategies, and came up with a brand extension theory model. Since then, their model has been repeatedly modified to suit the features of different industries.

Currently, brand extension strategies roughly fall into two categories: product line extension and franchise extension. The former is to improve the parent product or extend it to a similar product, while the latter is to extend the parent product to a product with different production principle, material and morphology. The two extension strategies are widely implemented across the Internet. The product line extension is manifested as the iterative update of Internet products. The franchise extension is evidenced by the launch of television and other hardware products by Leshi Internet Information and Technology Corp., Beijing, a leading Chinese online video company, and the extension of the QQ brand to music players, browsers and games.

To evaluate brand extension, Aaker and Keller set up the $\mathrm{A} \& \mathrm{~K}$ model to assess the correlation degree between the parent product and the extended product, and takes the perceived quality of the parent product and the correlation degree as the key to brand extension evaluation. Here, the perceived quality of the parent product refers to how much the consumer can perceive the image of the parent product. Aaker 
and Keller argued that the perceived quality of the parent product has a positive impact on consumer evaluation of brand extension, which agrees well with previous research on consumer-brand extension outcomes [1].

Cardozo suggested that consumer satisfaction is essential to successful marketing, marking the onset of integrated research on consumer satisfaction and marketing [2]. Consumer satisfaction is defined as the subjective satisfaction of the consumer after consuming certain products or services. In this paper, it is assumed that the satisfaction of the parent product at the PC terminal can reflect the perceived quality of the parent product, and the continuance intention of the extended product at the mobile terminal can express the consumer evaluation of the extended product. On this basis, the following hypothesis was put forward:

H1: The satisfaction of the parent product at the $\mathrm{PC}$ terminal has a positive impact on the continuance intention of the extended product at the mobile terminal.

The correlation degree between the extended product and the parent product refers to the similarity between the two entirely independent entities. Aaker and Keller held that the consumer evaluation of the extension effect is better at a higher correlation degree, i.e. the consumer find the extended product is highly similar to the parent product in production process, product form, product image, etc. Nevertheless, the Internet products at the PC terminal are the same with those at the mobile terminal, except in the terminal form. The two types of products are far from completely independent. Hence, the correlation degree between the extended product and the parent product cannot be directly applied to identify the reasons for Internet product consumers to transfer from the PC terminal to the mobile terminal.

According to Kent and Allen, the memory fragments on brand and product are distributed on the memory nodes of the consumer, and each node has its unique connections and strength [3]. The specific information can be obtained by tracking back along the connections, and the degree of backtracking depends on the strength between nodes. In this paper, the parent product at the PC terminal belongs to the same brand and service as the extended product at the mobile terminal. To perceive the parent product and the extended product as a whole, the consumer needs to acquire the specific information through the connections between different memory nodes on the brand and the product.

This paper attempts to replace "the correlation degree between the extended product and the parent product" with "the perceived integrity" as a measure of how strong the consumer perceives the similarity between the parent product at the PC terminal and the extended product at the mobile terminal. The perceived integrity is positively correlated with the continuance intention of the extended product at the mobile terminal. On this basis, the following hypothesis was put forward:

H2: The perceived integrity has a positive impact on the continuance intention of the extended product at the mobile terminal.

The parent product at the PC terminal and the extended product at the mobile terminal are more likely to be viewed as a whole product, if both of them are fully known to the consumer. The use of the whole product is extended thanks to the emergence of mobile terminals, which enhances the consumer perception of the product usefulness at the PC terminal, making the consumer more satisfied with the parent product at the $\mathrm{PC}$ terminal. On this basis, the following hypothesis was put forward:

H3: The perceived integrity has a positive impact on the satisfaction of the parent product at the PC terminal.

\subsection{Technology acceptance theory and continuance intention theory}

Inspired by the theory of reasoned action (TRA) [4], Davis proposed the technology acceptance model (TAM) based on the perceived ease-of-use and perceived usefulness, two key factors of the consumer acceptance of information systems [5]. The two factors respectively reflect how convenient and how useful an information system is in the eyes of the consumer. The TAM suggests that the consumer prefers an information system with high perceived ease-of-use and usefulness. In other words, the consumer is more willing to use an information system that seems useful and convenient to him/her.

Bhattacherjee et al. noted that the consumer acceptance of an information system hinges on the continuance intention rather than the first use behavior, and that the two factors belong to different phases. In 2001, Bhattacherjee developed the expectation confirmation model-information system continuance (ECM-ISC), which attributes the continuance intention of an information system to the consumer satisfaction and perceived usefulness of that system.

For the extended product at the mobile terminal, the consumer is more willing to use the product if it can be utilized easily in different scenarios. The more consumer-friendly the product, the higher the continuance intention of the consumer. On this basis, the following hypothesis was put forward:

H4: The perceived ease-of-use has a positive impact on the continuance intention of the extended product at the mobile terminal.

If a consumer is loyal to the parent product at the PC terminal, he/she must be familiar with the functions and operating procedures, and can quickly adapt to the extended product at the mobile terminal. By contrast, a consumer not satisfied by the parent product is naturally unwilling to use the extended product at the mobile terminal. The dissatisfaction also makes the consumer unfamiliar with the functions and operating procedures, suppressing the perceived ease-of-use of the extended product. On this basis, the following hypothesis was put forward:

H5: The satisfaction of the parent product at the PC terminal has a positive impact on the perceived ease-of-use of the extended product at the mobile terminal.

Both the TAM and the ECM-ISC agree that the information service quality directly bears on consumer behavior. The TAM evaluates the service quality by the perceived usefulness, while the ECM-ISC by the consumer satisfaction. In this paper, it is considered that both the perceived usefulness and consumer satisfaction are part of the information service value perceived by the consumer. Many studies [6-7] have demonstrated the direct or indirect positive impacts of consumer behavior on the perceived value.

To distinguish from the parent product at the PC terminal, the value of the extended product at the mobile terminal was defined as the new perceived value. On this basis, the following hypothesis was put forward:

H6: The new perceived value has a positive impact on the continuance intention of the extended product at the mobile terminal.

The TAM also believes that the perceived ease-of-use of 
information service is positively correlated with the consumer's perceived usefulness of the product. This correlation has been repeatedly proved by many scholars [89]. In this paper, the perceived usefulness is viewed as the consumer's recognition of the value of information service products. On this basis, the following hypothesis was put forward:

H7: The perceived ease-of-use of the extended product at the mobile terminal has a positive impact on the recognition of the new perceived value.

Observation shows that the consumer tends to regard the extended product and the parent product as a whole product at a high perceived integrity. This means the new features of the mobile terminal add value to the whole product. Taking the NetEase Cloud Music for example, the "My Songs" playlist can be synchronized in real time between the PC and mobile devices after the music player is extended to the mobile terminal. The consumer is allowed to listen to his/her playlist of the PC terminal anytime and anywhere, and synchronize his/her favorite songs to the phone. In the eyes of the consumer, the mobile app has brought new value to NetEase Cloud Music. However, the "new value" will not be sensed by the consumer if the perceived integrity is low. On this basis, the following hypothesis was put forward:

H8: The perceived integrity has a positive impact on the recognition of the new perceived value.

The perceived value is not a static variable. Facing similar information services on the Internet, the consumer may adopt the anchoring strategy: using a product only if it has a relative advantage, which is manifested as irreplaceability, over the anchored products [10-11]. The lower the irreplaceability of a product, the more unlikely for the consumer recognize the value of the product.

In this paper, the extended product is in rivalry with similar products at the mobile terminal, as well as the parent product at the PC terminal. Therefore, the product irreplaceability should cover the irreplaceability of the extended product against competitors at the mobile terminal and parent product at the PC terminal. When the consumer feels the extended product cannot be replaced by PC or mobile competitors, he/she will recognize a high new value of the extended product, and develop a high continuance intention. The same will happen if the consumer finds the extended product easy to use. On this basis, the following hypotheses were put forward:

H9: Perceived irreplaceability of the extended product at the mobile terminal has a positive impact on the new perceived value.

H10: Perceived irreplaceability of the extended product at the mobile terminal has a positive impact on the continuance intention.

H11: Perceived ease-of-use of the extended product at the mobile terminal has a positive impact on the perceived irreplaceability.

Under the above hypotheses, the author created a model on the willingness of Internet product consumers to transfer from the PC terminal to the mobile terminal (Figure 1).

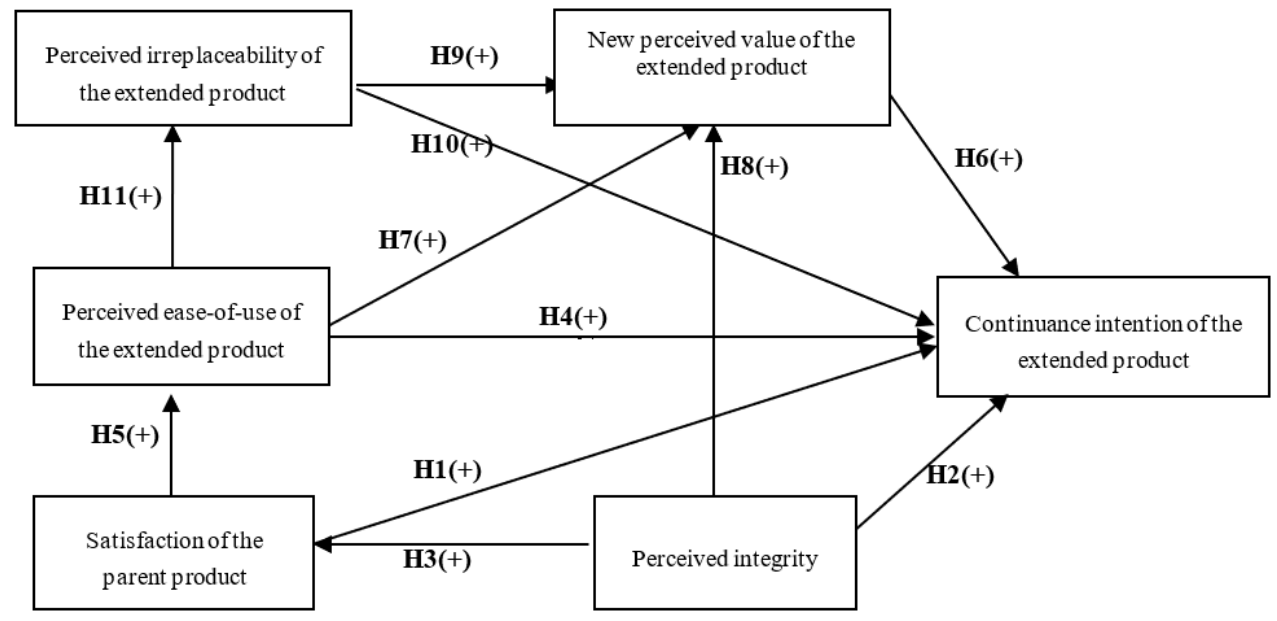

Figure 1. The model on the willingness of Internet product consumers to transfer from the PC terminal to the mobile terminal

\section{RESEARCH DESIGN}

\subsection{Measuring tool}

The questionnaire survey method was adopted to evaluate the new perceived value and irreplaceability, as well as other items from the existing studies. Each item was rated against a 7-point Likert scale ( $1=$ strongly disagree; $7=$ strongly agree). Table 1 lists the measurement indices and reference sources [12-15].

\subsection{Sampling and data collection}

This paper targets several Chinese Internet products, which have a high consumer coverage at the PC terminal and corresponding apps at the mobile terminal. Respondents choose an internet product to answer the questionnaire according to their familiarity.

The formal survey consists of a paper questionnaire survey and an online questionnaire survey. For convenience, the paper questionnaire survey was carried out by four teams, respectively in Guangdong, Gansu, Beijing and Jiangsu, while the online questionnaire survey was conducted through the online research platform www.wjx.cn.

A total of 507 questionnaires were collected, including 227 paper questionnaires and 280 online questionnaires. Among them, there are 456 valid questionnaires. The descriptive statistics of respondents are given in Table 2.

Considering the research background, the survey mainly focused on young people between 18 and 25. Almost all consumers in this age group are users of PC terminal apps before becoming heavy users of mobile terminal ones. 
Table 1. Measurement indices and reference sources

\begin{tabular}{|c|c|c|c|}
\hline Constructs & Items & scale & Reference \\
\hline $\begin{array}{l}\text { Satisfaction of the parent } \\
\text { product }\end{array}$ & $\begin{array}{l}\text { SA1 } \\
\text { SA2 } \\
\text { SA3 }\end{array}$ & $\begin{array}{l}\text { Overall, I am satisfied with the service of the PC terminal product. } \\
\text { The choice of using the service of the PC terminal product did not disappoint me. } \\
\text { I have a positive acceptance of the service of the PC terminal product. }\end{array}$ & $\begin{array}{c}\text { Bhattacherjee } \\
\text { (2001) [12] }\end{array}$ \\
\hline Perceived integrity & $\begin{array}{l}\text { PT1 } \\
\text { PT2 } \\
\text { PT3 }\end{array}$ & $\begin{array}{l}\text { As the products at the mobile terminal and the PC terminal form an organic whole, only using one of } \\
\text { them cannot achieve the best performance. } \\
\text { As the products at the mobile terminal and the PC terminal have strong complementarity, either one } \\
\text { cannot be omitted. } \\
\begin{array}{r}\text { As the products at the mobile terminal and the PC terminal have high correlation degree, they cannot } \\
\text { be separately used. }\end{array}\end{array}$ & $\begin{array}{l}\text { Peijian Song, } \\
\text { Cheng Zhang } \\
\text { (2009) [13] }\end{array}$ \\
\hline $\begin{array}{l}\text { New perceived value of } \\
\text { the extended product }\end{array}$ & $\begin{array}{l}\text { NV1 } \\
\text { NV2 } \\
\text { NV3 }\end{array}$ & $\begin{array}{l}\text { It meets my needs to port this product to the mobile terminal. } \\
\text { It brings me convenience to port this product to the mobile terminal. } \\
\text { It's helpful for me to port this product to the mobile terminal. }\end{array}$ & This Study \\
\hline $\begin{array}{l}\text { Perceived ease-of-use of } \\
\text { the extended product }\end{array}$ & $\begin{array}{l}\text { PE1 } \\
\text { PE2 } \\
\text { PE3 }\end{array}$ & $\begin{array}{l}\text { It's easy to learn how to use the mobile terminal product. } \\
\text { It does not require much effort to learn how to use the mobile terminal product. } \\
\text { It is easy to start with the operation of the mobile terminal product. }\end{array}$ & $\begin{array}{l}\text { Davis. (1989) } \\
\quad[5] \\
\text { Lee }(2003)[9]\end{array}$ \\
\hline \multirow[t]{2}{*}{$\begin{array}{l}\text { Perceived irreplaceability } \\
\text { of the extended product }\end{array}$} & $\begin{array}{l}\text { IR1 } \\
\text { IR2 } \\
\text { IR3 }\end{array}$ & $\begin{array}{l}\text { The extended product at the mobile terminal is not easily replaced by other products or methods. } \\
\text { Using other methods to replace the extended product at the mobile terminal, the effect is not good. } \\
\text { For me, the extended product at the mobile terminal has a high irreplaceability. }\end{array}$ & \multirow[t]{2}{*}{ This Study } \\
\hline & IR4 & No solution that is much better than the extended product at the mobile terminal. & \\
\hline $\begin{array}{l}\text { Continuance intention of } \\
\text { the extended product }\end{array}$ & $\begin{array}{l}\mathrm{CI} 1 \\
\mathrm{CI} 2 \\
\mathrm{CI} 3\end{array}$ & $\begin{array}{l}\text { I will continue to use the mobile terminal product. } \\
\text { I will not give up using the mobile terminal product. } \\
\text { I will not use other products to replace the mobile terminal product temporarily. }\end{array}$ & $\begin{array}{c}\text { Bhattacherjee } \\
\text { (2001) [12] }\end{array}$ \\
\hline
\end{tabular}

Table 2. Descriptive statistics of respondents

\begin{tabular}{cccc}
\hline Options & Features & Frequency $(\mathrm{N}=456)$ & Proportion (\%) \\
\hline \multirow{2}{*}{ Gender } & Male & 189 & 41.4 \\
& Female & 267 & 58.6 \\
\hline \multirow{2}{*}{ Phone system } & Android & 169 & 37.1 \\
& IOS & 287 & 62.9 \\
\hline \multirow{2}{*}{ Age (years) } & $<18$ & 8 & 1.8 \\
& $18-25$ & 323 & 70.8 \\
& $26-40$ & 102 & 22.4 \\
Education & $>40$ & 23 & 5.0 \\
& University (undergraduate, junior college) & 70 & 15.4 \\
& Graduate and above & 367 & 80.5 \\
& High school and below & 19 & 4.1 \\
\hline \multirow{2}{*}{ Occupation } & Student & 186 & 40.8 \\
& Liberal professions & 62 & 13.6 \\
& Company staff & 108 & 23.7 \\
\hline
\end{tabular}

\section{DATA ANALYSIS AND RESULTS}

In the Bartlett's test, the Kaiser-Meyer-Olkin (KMO) value was 0.843 , indicating that the test data were the suitable for factor analysis. Then, the principal factor method of varimax rotation was adopted to process the data, yielding the results in Table 3. It can be seen from the results that the load of each factor was much higher than that of any other factor, an evidence of the good validity of the scale.

The common-method variance of the scale was also tested, indicating that the first un-rotated extract factor had a variance of $33.84 \%$. Since the variance is less than $50 \%$ of the total explained variance of $81.83 \%$, there is no serious commonmethod variance of our scale.

The standard factor load of the latent variables was tested on the SPSS AMOS 21, and the results were collected into Table 4 . It can be seen that the average variance extracted
(AVE) was greater than 0.5 , while both composite reliability (CR) and Cronbach's alpha $(\alpha)$ were above 0.8 . Thus, the test scale enjoys good validity and reliability.

In addition, the discriminant validity of the scale was examined by the square root of the AVE and the correlation matrix between the factors. As shown in Table 5, the square root of the AVE of each factor was far greater than the correlation coefficient between factors. This means the test scale boasts a good discriminant validity.

The recommended and actual values of the fitting indices are shown in Table 6. Obviously, the actual value of each index was better than the recommended value, revealing the high fitness of the model.

All hypotheses, except H1, passed the significance test (Table 7). The test results of the structural model are displayed in Figure 2 below. 
Table 3. Rotational component matrix

\begin{tabular}{|c|c|c|c|c|c|c|}
\hline Indicators & $\begin{array}{l}\text { Perceived irreplaceability of } \\
\text { the extended product }\end{array}$ & $\begin{array}{l}\text { Perceived ease-of-use } \\
\text { of the extended product }\end{array}$ & $\begin{array}{c}\text { New perceived value } \\
\text { of the extended } \\
\text { product }\end{array}$ & $\begin{array}{l}\text { Satisfaction of the } \\
\text { parent product }\end{array}$ & $\begin{array}{l}\text { Perceived } \\
\text { integrity }\end{array}$ & $\begin{array}{l}\text { Continuance intention of } \\
\text { the extended product }\end{array}$ \\
\hline IR1 & .831 & .146 & .050 & -.012 & -.039 & .113 \\
\hline IR3 & .822 & -.009 & .079 & -.033 & .037 & .037 \\
\hline IR2 & .800 & .159 & .122 & -.050 & -.083 & .196 \\
\hline IR4 & .764 & -.026 & .154 & .069 & .130 & .128 \\
\hline PE2 & .072 & .899 & .233 & .077 & .033 & .153 \\
\hline PE3 & .082 & .869 & .176 & .110 & .040 & .129 \\
\hline PE1 & .092 & .861 & .198 & .105 & .037 & .193 \\
\hline NV2 & .166 & .242 & .862 & .119 & .094 & .187 \\
\hline NV3 & .124 & .213 & .855 & .095 & .105 & .219 \\
\hline NV1 & .150 & .215 & .834 & .097 & .148 & .208 \\
\hline SA3 & .017 & .019 & .082 & .893 & .121 & .050 \\
\hline SA1 & -.036 & .094 & .086 & .890 & .155 & .071 \\
\hline SA2 & -.011 & .168 & .095 & .872 & .155 & .097 \\
\hline PT1 & -.028 & .055 & .023 & .126 & .863 & .028 \\
\hline PT2 & -.001 & .024 & .124 & .157 & .861 & .161 \\
\hline PT3 & .080 & .019 & .150 & .143 & .856 & .128 \\
\hline $\mathrm{CI} 2$ & .213 & .168 & .288 & .087 & .071 & .818 \\
\hline $\mathrm{CI} 3$ & .095 & .164 & .085 & .083 & .228 & .804 \\
\hline CI1 & .240 & .202 & .316 & .087 & .063 & .790 \\
\hline
\end{tabular}

Table 4. Standard factor load (AVE, CR and $\alpha$ )

\begin{tabular}{|c|c|c|c|c|c|}
\hline Factors & Indicators & Factor Standard Load & AVE & $\mathrm{CR}$ & $\alpha$ \\
\hline \multirow{3}{*}{ Perceived integrity (PT) } & PT1 & 0.768 & \multirow{3}{*}{0.682} & \multirow{3}{*}{0.865} & \multirow{3}{*}{0.864} \\
\hline & PT2 & 0.869 & & & \\
\hline & PT3 & 0.837 & & & \\
\hline \multirow{3}{*}{ New perceived value of the extended product (NV) } & NV1 & 0.859 & \multirow{3}{*}{0.797} & \multirow{3}{*}{0.922} & \multirow{3}{*}{0.921} \\
\hline & NV2 & 0.933 & & & \\
\hline & NV3 & 0.885 & & & \\
\hline \multirow{3}{*}{ Satisfaction of the parent product (SA) } & SA1 & 0.882 & \multirow{3}{*}{0.741} & \multirow{3}{*}{0.895} & \multirow{3}{*}{0.895} \\
\hline & SA2 & 0.869 & & & \\
\hline & SA3 & 0.830 & & & \\
\hline \multirow{3}{*}{ Perceived ease-of-use of the extended product (PE) } & PE1 & 0.862 & \multirow{3}{*}{0.788} & \multirow{3}{*}{0.917} & \multirow{3}{*}{0.915} \\
\hline & PE2 & 0.965 & & & \\
\hline & PE3 & 0.831 & & & \\
\hline \multirow{4}{*}{ Perceived irreplaceability of the extended product (IR) } & IR1 & 0.835 & \multirow{4}{*}{0.668} & \multirow{4}{*}{0.889} & \multirow{4}{*}{0.889} \\
\hline & IR2 & 0.854 & & & \\
\hline & IR3 & 0.807 & & & \\
\hline & IR4 & 0.771 & & & \\
\hline \multirow{3}{*}{ Continuance intention of the extended product $(\mathrm{CI})$} & CI1 & 0.902 & \multirow{3}{*}{0.725} & \multirow{3}{*}{0.887} & \multirow{3}{*}{0.877} \\
\hline & $\mathrm{CI} 2$ & 0.908 & & & \\
\hline & $\mathrm{CI} 3$ & 0.723 & & & \\
\hline
\end{tabular}

Table 5. Correlations between latent variables.

\begin{tabular}{|c|c|c|c|c|c|c|}
\hline & PT & $\mathrm{NV}$ & SA & $\mathrm{PE}$ & IR & $\mathrm{CI}$ \\
\hline PT & 0.826 & & & & & \\
\hline NV & 0.316 & 0.893 & & & & \\
\hline SA & 0.382 & 0.286 & 0.861 & & & \\
\hline PE & 0.148 & 0.529 & 0.255 & $8^{0.88}$ & & \\
\hline IR & 0.055 & 0.356 & 0.001 & $6^{0.25}$ & 0.817 & \\
\hline CI & 0.314 & 0.613 & 0.247 & $1^{0.47}$ & 0.439 & $1^{0.85}$ \\
\hline
\end{tabular}

Table 6. The recommended and actual values of the fitting indices

\begin{tabular}{ccccccc}
\hline Model Fit & $\chi^{2} / \mathrm{df}$ & RMSEA & GFI & AGFI & CFI & NFI \\
\hline Recommended value & $<3$ & $<0.08$ & $>0.90$ & $>0.90$ & $>0.90$ & $>0.90$ \\
Actual value & 2.14 & 0.05 & 0.93 & 0.91 & 0.97 & 0.95 \\
\hline
\end{tabular}


Table 7. Results of hypotheses

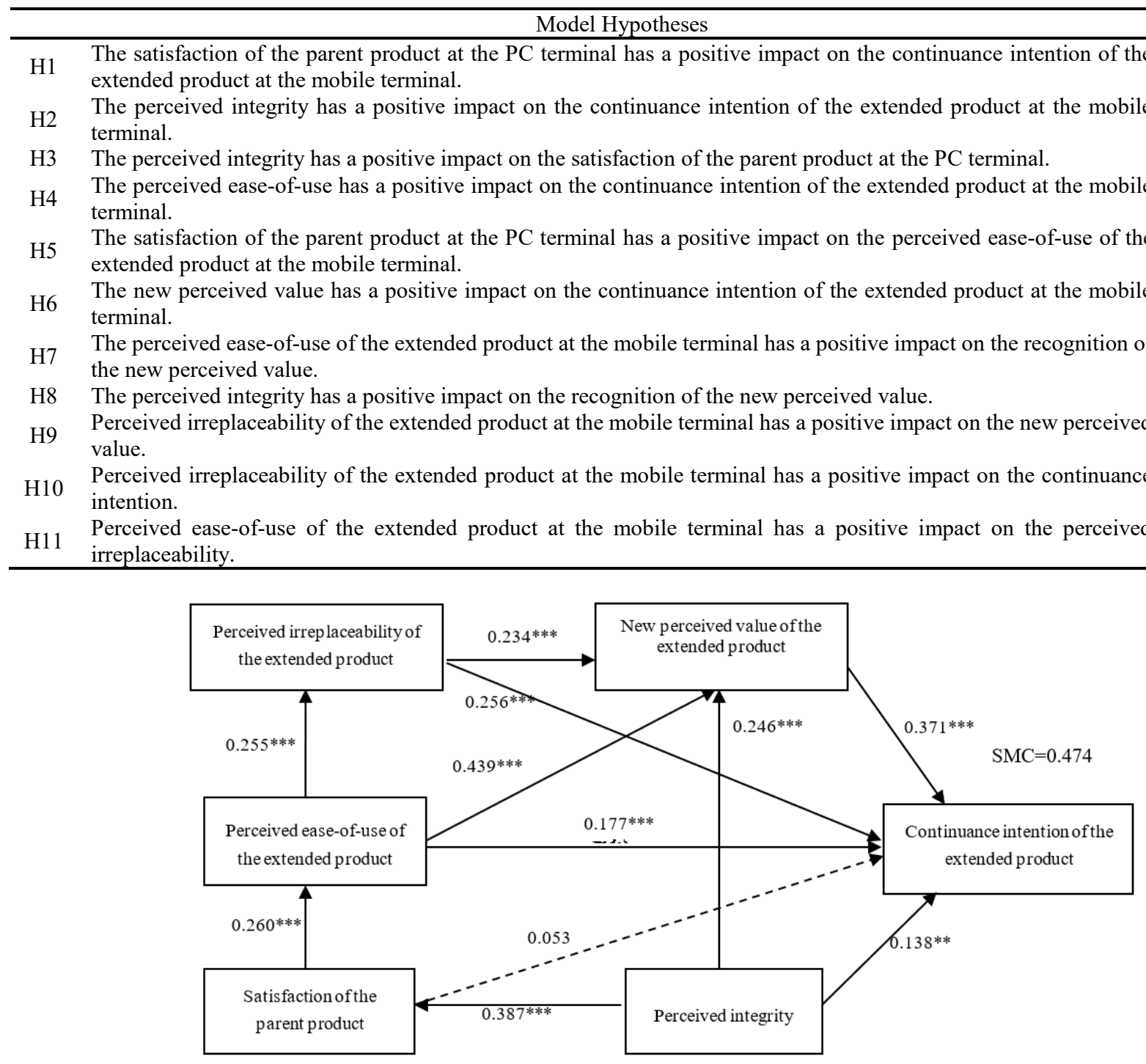

Figure 2. Test results of the structural model

\section{CONCLUSIONS}

This paper mainly discusses the behavior of consumers transferring from the parent product at the $\mathrm{PC}$ terminal to the extended product at the mobile terminal. Based on the classical theories of brand extension, technology acceptance and continuance intention, three new factors, namely, perceived integrity, irreplaceability and new value recognition, were introduced and a hypothetical model was put forward and tested through empirical analysis. By analyzing the relationships between various factors, the significant findings were summarized as follows.

Most importantly, consumer satisfaction of the parent product at the $\mathrm{PC}$ terminal has no direct impact on the continuance intention of the extended product at the mobile terminal. Instead, there is an indirect impact through the mediation of the perceived ease-of-use of the extended product, which is under a significant, positive impact from the satisfaction of the parent product.

The new perceived value has a significant, positive impact on the continuance intention of the extended product, while the irreplaceability positively affects the new perceived value and continuance intention.

The perceived integrity has a positive impact on the consumer satisfaction of the parent product, new perceived value of the extended product, as well as the continuance intention.

In addition, the perceived ease-of-use of the extended product has a positive impact on the new perceived value and the perceived irreplaceability.

The above findings shed new light on the efficient extension of the parent product at the PC terminal to the mobile terminal. The following suggestions were given to Internet information service providers.

(1) Considering the positive impact of perceived integrity on continuance intention, the connection between the parent product and extended product should be enhanced if the information services at the PC and mobile terminals have low perceived integrity. High-value functions should be added to products in both terminals based on the product features.

(2) Considering the positive impact of perceived easy-ofuse on continuance intention, the experience of mobile consumers must be emphasized in the extension of product to the mobile terminal. Taking video service products for 
instance, automatic caching under Wi-Fi should be enabled in view of the high cost of cellular data.

(3) Considering the positive impact of new perceived value on continuance intention, new functions with mobile features should be designed for the extended product at the mobile terminal. For example, the voice messaging and quick response $(\mathrm{QR})$ code-scanning of WeChat, the navigation of Baidu Map, and the photo uploading of Weibo all manifest mobile features.

The future research will replace the theoretical continuance intention with real consumer behavior and consider even more influencing factors.

\section{ACKNOWLEDGMENT}

This paper is supported by "the Fundamental Research Funds for the Central Universities", South-Central University for Nationalities (Grant Number: CSY19021).

\section{REFERENCES}

[1] Aaker, D.A., Keller, K.L. (1990). Consumer evaluations of brand extensions. The Journal of Marketing, 51(4): $27-$ 41. https://doi.org/10.2307/1252171

[2] Cardozo, R.N. (1965). An experimental study of customer effort, expectation, and satisfaction. Journal of Marketing Research, 2(3): 244-249. https://doi.org/10.2307/3150182

[3] Kent, R.J., Allen, C.T. (1994). Competitive interference effects in consumer memory for advertising: the role of brand familiarity. The Journal of Marketing, 58(3): 97105. https://doi.org/10.2307/1252313

[4] Fishbein, M., Ajzen, I. (1975). Belief, Attitude, Intention, and Behavior. Reading, MA: Addison-Wesley.

[5] Davis, F.D. (1989). Perceived usefulness, perceived ease of use, and user acceptance of information technology. MIS Quarterly, 13(3): 319-340. https://doi.org/10.2307/249008

[6] Zhao, H., Su, C., Hua, Z. (2016). Investigating continuance intention to follow a brand micro-blog: Perceived value and social identification. Information
Development, 32(5):

$1428-1441$

https://doi.org/10.1177/0266666915602522

[7] Hong, J., Lin, P., Hsieh, P. (2017). The effect of consumer innovativeness on perceived value and continuance intention to use smartwatch. Computers in Human Behavior, 67: 264-272. https://doi.org/10.1016/j.chb.2016.11.001

[8] Dishaw, M.T., Strong, D.M. (1999). Extending the technology acceptance model with task-technology fit constructs. Information \& Management, 36(1): 9-21. https://doi.org/10.1016/S0378-7206(98)00101-3

[9] Lee, Y., Kozar, K.A., Larsen, K.R. (2003). The technology acceptance model: Past, present, and future. Communications of the Association for Information Systems, 12(1): 752-780.

[10] Lee, Y., Hsieh, Y., Hsu, C. (2011). Adding innovation diffusion theory to the technology acceptance model: Supporting employees' intentions to use e-learning systems. Journal of Educational Technology \& Society, 14(4):

124-137. https://doi.org/10.3724/SP.J.1011.2008.00482

[11] Liu, W., Zhang, L., Ding, L., Wang, C. (2014). Information service continued use model: based on competition view. Pakistan Journal of Statistics, 30(5): 607-622.

[12] Bhattacherjee, A. (2001). Understanding information systems continuance: An expectation-confirmation model. MIS Quarterly, 25(3): 351-370. https://doi.org/10.2307/3250921

[13] Song, P., Zhang, C., Chen, W., Huang, L. (2009). Understanding usage-transfer behavior between nonsubstitutable technologies: evidence from instant messenger and portal. IEEE Transactions on Engineering Management, 56(3): 412-424. https://doi.org/10.1109/TEM.2009.2023084

[14] Song, P., Zhang, C., Xu, Y.C., Huang, L. (2010). Brand extension of online technology products: Evidence from search engine to virtual communities and online news. Decision Support Systems, 49(1): 91-99. https://doi.org/10.1016/j.dss.2010.01.005

[15] Stewart, K.J. (2003). Trust transfer on the world wide web. Organization Science, 14(1): 5-17. https://doi.org/10.1287/orsc.14.1.5.12810 